\title{
Condicionantes da Dinâmica Produtiva de Feijão e Arroz no Brasil: um estudo com dados em painel
}

\author{
Dilamar Dallemole* \\ José Ramos Pires Manso** \\ Alexandre Magno de Melo Faria***
}

Resumo: A integração das cadeias produtivas é responsável por significativas mudanças no processo produtivo agropecuário, pois as diversidades e as exigências supranacionais passam a integrar a produção de commodities agrícolas. Associada a essa questão, o aumento na demanda por alimentos, bem como, da qualidade dos mesmos, intensificam as exigências ao setor produtivo. Susceptíveis a tais condições, os mercados de feijão e arroz no Brasil, assim como nos demais países, ajustam-se e evoluem de acordo com os novos paradigmas. Tratam-se de expressivos mercados, portanto, faz-se necessário conhecer os determinantes da produção e compreender a dinâmica das relações destes, bem como, os possíveis impactos, principalmente para a agricultura, considerado setor chave para a seguridade alimentar. Sob esse aspecto, o escopo central tende para a determinação dos condicionantes da produção de feijão e arroz, no sentido de captar os fatores de maior influência. Para tanto, foi empregada a ferramenta de análise com Dados em Painel, no sentido de identificar quais categorias são responsáveis pelas alterações na oferta nestes mercados. Os resultados apontam para a necessidade de políticas moderadas de ajuste de câmbio, incentivo as exportações e ao consumo, pois tratam-se dos fatores mais importantes no que se refere a impactos sobre a produção. A correlação positiva destes, em relação à produção, tende a estimular o setor produtivo e o crescimento e fortalecimento destes mercados.

Palavras chave: Feijão; Arroz; Produção; Dados em Painel; Brasil.

Classificação JEL: R10

Professor Associado e Coordenador do Programa de Pós-graduação em Agronegócios e Desenvolvimento Regional da Faculdade de Economia, da Universidade Federal de Mato Grosso (UFMT). E-mail: dilamar@ufmt.br

* Professor Catedrático de Nomeação definitiva (com tenure) do Departamento de Gestão e Economia da Universidade da Beira Interior. E-mail: pmanso@ubi.pt

Professor Adjunto IV da Faculdade de Economia da UFMT, Campus Cuiabá. E-mail: dr.melofaria@ 
232 D. Dallemole; J. R. P. Manso; A. M. de M. Faria - Condicionantes da dinâmica produtiva ...

Conditions of dynamic production of bean and rice in Brazil: a panel data approach

\begin{abstract}
The integration of supply chains is responsible for significant changes in the agricultural production process, because the diversities and supranational requirements become part of the production of agricultural commodities. Associated with this issue, the increase in demand for food, as well as its quality, enhances the productive sector requirements. Susceptible to such conditions, the markets for beans and rice in Brazil, as in other countries, adjust and evolve according to new paradigms. These are significant markets, so it is necessary to know the determinants of production and to understand the dynamics of these relationships, as well as the possible impacts, mainly for agriculture, industry considered key to food security. In this respect, the central scope tends to determine the conditions of production of beans and rice, in order to capture the most influential factors. Therefore, we used the analysis tool with Panel Data, in order to identify which categories are responsible for changes in supply in these markets. The results point to the need for moderate political adjustment rates, encouraging exports and consumption, as these are the most important factors with regard to impacts on production. The positive correlation of these in relation to production, tends to stimulate the productive sector and the growth and strengthening of these markets.
\end{abstract}

Keywords: Beans, Rice, Production, Panel Data; Brazil.

JEL Classification: R10

\title{
1 Introdução
}

Tanto o Brasil como os demais países passam por um processo de mudanças estruturais, devido à progressiva globalização e liberalização do comércio mundial, além das mudanças tecnológicas, das reformas políticas e do surgimento de novas demandas de qualidade e segurança alimentar para mercados cada vez mais exigentes. A integração das cadeias produtivas tem sido responsável por significativas transformações no processo produtivo agropecuário, pois as diversidades e as exigências supranacionais passaram a integrar a produção de alimentos em todas as partes do mundo.

De acordo com os relatórios da Food and Agriculture Organization (FAO), a preocupação com a segurança alimentar e a saúde no mundo passam a exigir maior atenção, considerando o aumento na demanda por alimentos, bem como, a qualidade dos mesmos. Com a internacionalização das economias, a distribuição dos alimentos passou a ser global e, por isso, se um alimento se torna perigoso para a saúde, o risco de disseminação de doença ou infecções é mais elevado. Nesse sentido, a atenção deve ser dispendida não somente na distribuição dos alimentos, mas também em seu processo produtivo.

A atenção ao sistema produtivo agropecuário intensificou-se a partir de então, 
considerando a importância do controle de qualidade, advinda das diferentes exigências dos diversos mercados e seus aspectos culturais e legais. As cadeias produtivas de alimentos passaram a ter de se adequar para manter seus mercados ou para se inserir em novos, um fator que intensificou a inovação, por exemplo, na agricultura.

Estas questões são perceptíveis quando observadas as relações comerciais com a Europa e Estados Unidos, por exemplo. A rastreabilidade bovina, a restrição ao uso de determinados pesticidas e herbicidas, ou até mesmo fertilizantes, são exigências de mercado que se transformam em novos condicionantes que implicam sobre o processo produtivo, fator que os principais países exportadores devem considerar para continuar ascendendo estes mercados mais exigentes.

Tais condicionantes passam a compor a estrutura de custos produtivos e de distribuição das cadeias de alimentos, compondo uma nova dinâmica e uma nova realidade produtiva, com expressivos investimentos em tecnologia e inovação. Nem todos os setores corresponderam, entretanto, alguns se destacam e tornam-se importantes geradores de emprego e renda para a economia de seu país. É o caso da produção de feijão e arroz no Brasil, Estados Unidos, Argentina e em alguns países europeus, como Alemanha França, Espanha, Holanda, Itália e Portugal. Tratam-se de significativos mercados produtores, consumidores, exportadores e/ou importadores destas commodities.

A décadas o Brasil mantem relações comerciais com os referidos países, exportando e/ou importando feijão e arroz, dentre outros produtos, ao mesmo tempo que mantém uma pauta de importações oriundas destes mesmos locais. Alguns efeitos diretos são percebíveis, como o saldo positivo na balança comercial brasileira, a geração de renda, o combate ao êxodo rural, contudo, identificam-se preços crescentes dos alimentos, expressivo crescimento do mercado de herbicidas e fertilizantes químicos.

Com a população mundial ainda em fase ascendente e o crescimento econômico das economias, mantém-se uma tendência de intensificação da demanda e da pressão por mais alimentos. Nesse sentido, faz-se necessário conhecer os condicionantes e a dinâmica das relações nos referidos mercados, bem como o impacto socioeconômico, principalmente para a agricultura, setor chave para a seguridade alimentar. Sob esse aspecto, o escopo central tende para a determinação dos condicionantes da produção de feijão e arroz, no sentido de captar os fatores de maior influência na determinação de seus processos de produção e comercialização.

Limitar-se-á aos referidos mercados e países, devido a existência de transações comerciais para os referidos produtos que já perduram por várias décadas. Este fator permite o emprego do modelo de análise de dados em painel, capaz de identificar os principais condicionantes da produção e das relações nestes mercados, assim como, de avaliar tendências futuras, importantes para o planejamento. A escolha deste grupo de países se justifica pelo fato de serem mercados mais exigentes e, por isso, responsáveis pela qualificação dos produtos e dos processos produtivos.

Considerando o objetivo proposto, a caracterização destes mercados, a distri- 
buição e consumo destas commodities nos países selecionados demandam uma abordagem prévia para o entendimento do contexto das relações comerciais históricas entre os países relacionados. Posteriormente, apresentar-se-á uma discussão conceitual acerca dos principais fatores analisados, no intuito de apresentar a inter-relação e o comportamento no mercado, seguido do modelo de análise de dados em painel, detalhando os procedimentos metodológicos para, na seção final, apresentar os principais resultados e considerações a respeito da produção e comercialização nestes mercados.

Os resultados obtidos permitem realizar algumas reflexões sobre as tendências e comportamento destes mercados que extrapolam o grupo de países analisados. A identificação dos fatores com maior significância na determinação da produção agem como fatores explicativos de comportamentos, que podem ser considerados em outros estudos ou em ações focadas em corrigir limitações comerciais impostas pelos mercados globalizados, inclusive para outros produtos.

\section{Perspectivas acerca dos mercados de feijão e arroz}

O mercado internacional de commodities desenvolve-se e integra sua cadeia produtiva a cada ano, num ambiente cada vez mais dinâmico, fortalecido e importante para a sócio economia dos países agroexportadores. Não obstante, estão as discussões acerca da produção e consumo de alimentos, mais precisamente voltadas a seguridade alimentar, que direta ou indiretamente estão ligadas à produção e comercialização de commodities, seja para matéria-prima ou consumo.

Dentre os principais mercados pode-se destacar o de feijão e arroz, com grande importância para a seguridade alimentar, entretanto, obedecem a padrões de consumo e preferências distintas, considerando as diversas particularidades locais, ou mesmo culturais. Tratam-se de especificidades importantes, responsáveis por algumas assimetrias, contudo, de modo geral, são mercados com comportamentos semelhantes, cuja lei da oferta e da procura determinam os níveis de preço e qualidade, as necessidade de comercialização e padrões alimentares.

No caso do feijão, considerando os relatórios da Companhia Nacional de Abastecimento (CONAB), a inexpressiva importância comercial e a falta de conhecimento limitam a expansão deste mercado em países considerados de primeiro mundo. Outra questão importante é o fato dos principais países produtores também serem os maiores consumidores, limitando o excedente para a exportação. Já o arroz é considerado uma das principais fontes de energia para mais da metade da população mundial. De acordo com dados do United States Department of Agriculture (USDA), a safra mundial de arroz superou os 465 milhões de toneladas em 2011, número aproximado do consumo para o mesmo período que foi de 458 milhões. Em 2012, o arroz representou $73,29 \%$ da energia para o Camboja, 29,99\% para a China e 12,09\% para o Brasil (CONAB, 2013). Trata-se de um mercado bem mais denso que o do feijão; entretanto, em alguns casos é possível identificar a complementariedade entre ambos, com a composição de pratos típicos em algumas regiões brasileiras. 
Nos países estudados é possível identificar estas disparidades, inclusive com o declínio da produção de feijão em grande parte dos países europeus entre 1996 e 2010, como pode ser observado na Tabela 1. Brasil e EUA estão entre os principais produtores de feijão e arroz, inclusive percebe-se a evolução na produção de feijão de 2,4 para 3,1 e 1,2 para 1,4 milhões de toneladas no Brasil e EUA, respectivamente.

A tendência é semelhante para Brasil e EUA no mercado de arroz, entretanto, os países europeus apresentam incremento da produção no período analisado. A única exceção fica por conta de Portugal, que apresentou ligeira queda e da Holanda, onde não há registro de produção de arroz pelas principais instituições internacionais no período estudado.

No tocante ao consumo, os hábitos são significativamente diversificados, inclusive em regiões de uma mesmo país. De acordo com estudos da Conab (2013), o maior consumo de feijão preto está no Rio de Janeiro e Rio Grande do Sul, seguido em menor escala por Paraná, Santa Catarina e Espírito Santo. Já o feijão Caupi, por exemplo, é consumido tipicamente na Região Nordeste do Brasil.

Tabela 1. Produção de Feijão e Arroz, 1996 e 2010 (toneladas).

\begin{tabular}{l|cc|cc}
\hline \multirow{2}{*}{\multicolumn{1}{c|}{ PAÍS }} & \multicolumn{2}{c|}{ FEIJÃO } & \multicolumn{2}{c}{ ARROZ } \\
\cline { 2 - 6 } & 1996 & 2010 & 1996 & 2010 \\
\hline Argentina & 218.313 & 338.120 & 986.000 & 1.240 .600 \\
\hline Brasil & 2.449 .400 & 3.158 .910 & 8.643 .800 & 11.236 .000 \\
\hline França & 9.693 & 5.531 & 115.100 & 118.500 \\
\hline Itália & 23.137 & 13.181 & 1.424 .000 & 1.516 .400 \\
\hline Holanda & 7.839 & 6.400 & - & - \\
\hline Portugal & 15.075 & 2.000 & 172.230 & 170.200 \\
\hline Espanha & 29.400 & 15.100 & 734.000 & 926.400 \\
\hline EUA & 1.266 .000 & 1.442 .470 & 7.783 .600 & 11.027 .000 \\
\hline MÉDIA & 502.357 & 622.714 & 2.482 .342 & 3.279 .388 \\
\hline
\end{tabular}

Dentre os países estudados o Brasil detém o maior consumo, exacerbadamente superior aos demais, inclusive dos EUA que consome, em média, menos de $70 \%$ da produção de feijão, tendência acompanhada pelo consumo de arroz, algo em torno de apenas 33\% da produção. Da mesma forma que no caso do feijão, o Brasil também consome praticamente toda a produção de arroz. Por outro lado, os países europeus apresentam um nível de consumo muito superior à produção, principalmente França e Portugal no caso do arroz e, além destes, Itália e Espanha no que se refere a feijão (Tabela 2). 
236 D. Dallemole; J. R. P. Manso; A. M. de M. Faria - Condicionantes da dinâmica produtiva ...

Tabela 2. Consumo de Feijão e Arroz, 1996 e 2010 (toneladas).

\begin{tabular}{l|c|c|c|c}
\hline \multirow{2}{*}{ PAÍS } & \multicolumn{2}{c|}{ FEIJÃO } & \multicolumn{2}{c}{ ARROZ } \\
\cline { 2 - 5 } & 1996 & 2010 & 1996 & 2010 \\
\hline Argentina & 6.268 & 17.135 & 333.480 & 355.189 \\
\hline Brasil & 3.143 .120 & 2.857 .001 & 9.258 .665 & 9.700 .622 \\
\hline França & 52.071 & 53.790 & 295.514 & 414.294 \\
\hline Itália & 91.644 & 96.817 & 495.889 & 516.978 \\
\hline Holanda & 7.000 & 6.067 & 152.167 & 80.284 \\
\hline Portugal & 29.207 & 26.439 & 210.534 & 251.796 \\
\hline Espanha & 78.345 & 60.020 & 502.718 & 493.528 \\
\hline EUA & 916.600 & 980.000 & 3.225 .126 & 3.657 .723 \\
\hline MÉDIA & 540.532 & 512.159 & 1.809 .262 & 1.933 .802 \\
\hline
\end{tabular}

A proximidade entre os países europeus também facilita o comércio, entretanto, dentre os principais fornecedores de commodities aos países europeus estão Brasil, EUA e Argentina. Este último país exporta, por exemplo, cerca de 90\% da sua produção de feijão branco, grande parte para o mercado europeu, onde Espanha é o maior consumidor. Já o feijão preto não é consumido na Argentina, sendo exportado em sua totalidade e, em grande parte, para o Brasil e a Venezuela (CONAB, 2013).

No caso do arroz o Brasil é praticamente autossuficiente, no entanto, devido ao consumo expressivo, as importações devem atingir 542 mil toneladas (CONAB, 2013). Dentre os países estudados, os EUA são os principais exportadores, inclusive com volume crescente entre 1996 e 2010, conforme registro da FAO, cujos dados encontram-se dispostos na Tabela 4.

Em 2010 as exportações de feijão e arroz dos EUA representaram 28,2\% e $34,3 \%$, respectivamente. De acordo com dados da FAO (2012), na grande maioria dos casos, os preços apresentam-se crescentes no período de 1996 a 2010, uma tendência natural destes mercados, que apresentam demanda crescente e, em alguns casos, oferta insuficiente. Pode-se dizer que a Argentina é o único caso outlier, uma vez que apresenta queda no preço pago aos produtores de feijão. 
Tabela 3. Exportações de Feijão e Arroz, 1996 e 2010 (toneladas).

\begin{tabular}{l|c|c|c|c}
\hline \multirow{2}{*}{\multicolumn{1}{c|}{ PAÍS }} & \multicolumn{2}{c|}{ FEIJÃO } & \multicolumn{2}{c}{ ARROZ } \\
\cline { 2 - 5 } & 1996 & $\mathbf{2 0 1 0}$ & 1996 & 2010 \\
\hline Argentina & 154.981 & 326.549 & 259.394 & 473.426 \\
\hline Brasil & 5.180 & 4.302 & 21.811 & 422.550 \\
\hline França & 8.672 & 3.932 & 74.180 & 83.955 \\
\hline Itália & 3.483 & 5.557 & 608.277 & 813.009 \\
\hline Holanda & 29.734 & 16.022 & 113.420 & 117.483 \\
\hline Portugal & 2.754 & 13.244 & 10.336 & 30.732 \\
\hline Espanha & 3.137 & 4.093 & 175.989 & 288.463 \\
\hline EUA & 354.486 & 406.957 & 2.640 .356 & 3.782 .510 \\
\hline MÉDIA & 70.303 & 97.582 & 487.970 & 751.516 \\
\hline & \multicolumn{3}{c}{ Fonte: FAO, 2012. } \\
\hline
\end{tabular}

No caso do feijão, os preços em 2011configuraram-se abaixo do ideal, inclusive abaixo do preço mínimo. O Governo Federal teve de intervir no mercado, comprando parte do excedente da produção, fato que, associado à queda da produção da safra 2012, proporcionou a alavancagem dos preços. Já no caso do arroz, os preços sustentaram-se em patamares competitivos, contudo, algumas medidas de sustentação de preços do Governo Tailandês podem pressionar os preços na safra 2013 (CONAB, 2013).

Tabela 4. Preço ao Produtor do Feijão e Arroz, 1996 e 2010 (US\$/ton.).

\begin{tabular}{l|c|c|c|c}
\hline \multirow{2}{*}{ PAÍS } & \multicolumn{2}{c|}{ FEIJÃO } & \multicolumn{2}{c}{ ARROZ } \\
\cline { 2 - 5 } & 1996 & 2010 & 1996 & 2010 \\
\hline Argentina & $1.222,82$ & 953,89 & 210,31 & 239,34 \\
\hline Brasil & 520,13 & 903,65 & 175,94 & 328,01 \\
\hline França & $1.039,83$ & $1.384,48$ & 381,43 & 336,47 \\
\hline Itália & $1.480,00$ & $2.315,95$ & 469,48 & 517,98 \\
\hline Holanda & 441,28 & 903,43 & 338,61 & 347,32 \\
\hline Portugal & $1.133,58$ & $1.545,66$ & 442,51 & 354,26 \\
\hline Espanha & $1.813,34$ & $2.331,64$ & 426,27 & 337,64 \\
\hline EUA & 508,32 & 565,44 & 208,04 & 269,40 \\
\hline MÉDIA & $1.019,91$ & $1.363,02$ & 331,57 & 341,30 \\
\hline
\end{tabular}

Fonte: FAO, 2012. 
De modo geral, o aumento da produção de feijão e arroz são importantes para suprir a demanda insatisfeita por alimentos no mundo. O crescimento demográfico e o aumento da renda pressionam o setor produtivo, que demanda certo lapso temporal para responder, sendo necessária a regulamentação por meio dos estoques internacionais. Ademais, existem pressões exógenas ao mercado de alimentos, portanto, é natural que haja a pressão nos preços, pois o custo de oportunidade tende a direcionar a produção para os setores com maior rentabilidade e o custo dos alimentos pode elevar-se, também, em virtude do comportamento destes mercados paralelos. $\mathrm{O}$ fato de conhecer os condicionantes da produção de commodities agrega informações importantes, no sentido de combater as influências de mercado e otimizar os esforços no sentido de diminuir a pressão por alimentos, ou tornando mais eficiente o seu suprimento.

\section{Aspectos relevantes acerca da teoria econômica}

Considerando que cada categoria econômica possui uma conduta específica, impacta ao mesmo tempo que é sensitiva as alterações do mercado, em um primeiro momento, prima-se pelo entendimento destes comportamentos, para no segundo momento, compreender a influência no processo produtivo. Para tanto, a teoria econômica é uma importante base analítica e dará suporte ao entendimento do comportamento da taxa de câmbio, consumo, exportações, importações, PIB, renda per capita, preço, tecnologia e população.

Contudo, a análise deve ser dinâmica, considerando que as categorias não estão dissociadas umas das outras. Uma alteração na taxa de câmbio, por exemplo, tende a provocar alterações nos preços, cuja influência ainda tende para alterações nas exportações e importações. Este efeito ainda pode causar impactos no consumo e, consequentemente, na produção, que também pode ser impactada pelo aumento da demanda, motivada pelo aumento do número de consumidores.

Quando a oferta e a demanda por moeda estrangeira estiverem estáveis, tem-se uma taxa cambial constante, que determinará as relações comerciais de uma forma estável. Caso a oferta de moeda estrangeira passe a ser inferior à demanda, a tendência é de que haja uma valorização desta moeda estrangeira. Neste caso, a taxa de câmbio aumenta e os bens domésticos se tornam atrativos no mercado internacional, uma vez que são necessárias menos unidades monetária de moeda estrangeiras que o normal para a aquisição da mesma quantidade de bens, considerando que o poder de compra da moeda estrangeira se torna mais elevado. Por outro lado, a moeda doméstica perde poder de compra e são necessárias mais unidades monetárias para a aquisição da mesma quantidade de bens; logo, o processo de importação passa a ser mais oneroso (RATTI, 2004).

De acordo com a teoria econômica, além do câmbio, os preços externos também são considerados determinantes das exportações. Preços externos crescentes tendem a estimular as exportações, cuja variação afeta diretamente a produção. Se o 
nível de exportações aumenta, a renda tende a aumentar e se as exportações caem, a renda também tende a cair. Tais variações ainda podem provocar alterações no saldo comercial, a ponto de tornar a Balança Comercial superavitária, ou diminuir o déficit (BLANCHARD, 2011). Cabe destacar que o efeito pode ser inverso em decorrência de queda nos preços externos.

Entretanto, o saldo comercial não é somente dependente das exportações. Alterações nas importações implicam em uma variação, que pode ser positiva ou negativa, além de causar impactos na produção. $\mathrm{O}$ aumento da renda interna, cuja principal unidade de medida é o PIB per capita, pode estimular o consumo de produtos importados, principalmente, quando este excedente na renda não tende a ser canalizado para investimentos. Neste caso, com a renda aumentando, a demanda doméstica por bens pode ir além da produção e as pessoas passam a consumir produtos estrangeiros (BLANCHARD, 2011

A importância de uma Balança Comercial com crescentes superávits está no fato de que há um fortalecimento do mercado interno, considerando que a produção é crescente para atender as exportações e a parcela da renda gerada permanece no país, pois as importações não possuem o mesmo dinamismo. Significa que tem-se aumento de produção, com o aumento das exportações superiores ao aumento das importações.

Para fortalecer a balança comercial, por exemplo, o governo pode adotar uma política de desvalorização cambial, ou seja, uma depreciação da moeda nacional em relação a moeda internacional. Esta medida faria com que os produtos nacionais ficassem mais competitivos internacionalmente; logo as exportações nacionais tenderiam a aumentar. $\mathrm{O}$ aumento das exportações, mantendo-se as importações constantes, ou pelo menos com aumento inferior as exportações, provocará um aumento no saldo, fortalecendo assim a balança comercial. Esta medida por si só já poderia causar o aumento da renda, mas se o governo ainda quiser aumentar mais a renda, pode adotar uma política fiscal expansionista com o aumento em seus gastos, promovendo um aumento do consumo e, em parte, dos investimentos. Porém, vale lembrar que estas medidas devem provocar aumento de preços, da taxa de juros e até gerar inflação, colocando em risco a situação da economia no médio ou longo prazo, obrigando o próprio governo a interferir novamente na economia com uma política monetária. Mas se estas políticas, cambial e fiscal, forem dosadas corretamente elas conseguirão atingir seus objetivos, que é o fortalecimento da balança comercial e aumento da produção (BLANCHARD, 2011).

Os gastos privados tenderiam a acompanhar esta tendência de aumento, uma vez que as empresas são estimuladas a produzir para exportar em virtude do ganho de competitividade internacional, resultante da desvalorização cambial. Já, em um segundo momento, os gastos públicos devem diminuir até o ponto de neutralizar o efeito sobre os preços, para evitar que a inflação fuja do controle. De qualquer forma, há uma tendência de aumento de preços e do consumo, outros dois condicionantes da produção (BLANCHARD, 2011). 
As discussões acerca do comportamento do consumo foram desenvolvidas na década de 1950 por Milton Friedman, que a chamou de teoria do consumo da renda permanente e por Franco Modigliani, que a chamou de teoria do consumo do ciclo de vida. De acordo com estes autores, o consumo é uma função crescente da riqueza total e, também, uma função crescente da renda.

Sobre este aspecto, o consumo tende a variar em virtude das flutuações da renda atual, ou seja, a renda constitui o principal determinante do consumo agregado: quanto maior a renda, maior tende a ser o consumo. Contudo, em alguns casos, mesmo sem alterações na renda o consumo pode aumentar em virtude das expectativas com relação ao futuro, sendo que para isso as pessoas tendem a usar parte de sua riqueza (KEYNES, 1996).

Qualquer que seja a forma de motivação, o aumento do consumo passa a ser determinante na alteração de sua oferta. Contudo, as variações nem sempre são semelhantes se observadas as características dos produtos. Em caso de um bem substituto, um aumento na renda pode implicar em queda no consumo, pois haverá substituição por um bem superior. Isso pode acontecer também, em virtude do aumento no seu preço, pois o mesmo pode ser substituído por outro mais barato (PINDYCK e RUBINFELD, 2010). Neste caso, o aumento da renda e do preço não estimulam o aumento da oferta deste bem, tendência natural da maioria dos produtos.

Já no caso de bens complementares, o aumento da renda pode acarretar em aumento no consumo e, consequentemente, pode impulsionar o aumento na sua oferta, o que pode acontecer complementarmente a outro bem. Entretanto, caso haja aumento no seu preço, o efeito tende a ser inverso e pode se estender aos demais complementares (PINDYCK e RUBINFELD, 2010).

Contudo, de modo geral, o aumento da renda tende a acarretar no aumento do consumo, seja substituindo um bem pelo outro ou não. Para Keynes (1996), o consumo depende da Lei Psicológica Fundamental que, de acordo com os níveis de renda, determinam os níveis de poupança e consumo das famílias. É desta relação que se origina outra significativa contribuição keynesiana: a Propensão Marginal a Consumir. Apesar do aumento da renda ocasionar em aumento da poupança, o consumo também cresce, entretanto, em proporções variadas, de acordo com cada nível de renda.

As contribuições de Marx (1996) já alertavam para a importância das variações no preço para a reprodução do sistema capitalista. $\mathrm{O}$ aumento nos preços era fundamental para o aumento da mais-valia e a sustentação do sistema de reprodução ampliada. Fato corroborado posteriormente pelos economistas clássicos e neoclássicos, tendo em vista que o aumento de preço proporcionaria maiores lucros, necessários a ampliação dos investimentos e, consequentemente, da produção.

Entretanto, em uma economia globalizada, com mercados cada vez mais competitivos, o aumento necessário dos lucros pode ocorrer, não em virtude do aumento de preços, mas sim pela diminuição dos custos. Em casos específicos o aumento 
dos preços pode acarretar em perda de competitividade em mercados menores de concorrência perfeita, ou pouco diferenciados. É nestas ocasiões que as inovações tecnológicas são consideradas como importantes fatores de lucratividade. A geração de tecnologia possui paradigmas marcados pelas oportunidades tecnológicas e alguns procedimentos básicos de como explorá-las; variam de acordo com o setor e o seu grau de desenvolvimento. O potencial de aproveitamento decorre da cumulatividade das competências tecnológicas adquiridas. Se estes procedimentos ocorrerem de maneira eficaz, aumentam as possibilidades de se atingir a fronteira tecnológica. (CARIO, 1995).

Esta capacitação tecnológica é capaz de fazer um setor produtivo tornar-se competitivo e não está relacionada somente ao maquinário. A difusão tecnológica e os investimentos devem contemplar o capital humano, com melhorias do sistema educacional, para que os experimentos tecnológicos sejam bem sucedidos. Isto significa ampliar gastos em P\&D, em relação ao estoque de conhecimentos e pessoal qualificado (GUIMARÃES, 2001).

Especificamente, no caso da produção agrícola, a tecnologia pode ser uma importante aliada no aumento da produtividade. $\mathrm{O}$ incremento da produção por área significa aumento de renda e, por consequência, dos lucros. Em muitos casos, a tecnologia ainda é responsável pela redução nos custos de produção agrícola, fato este que estabelece uma segunda via, atuando, também, como um determinante da produção (SILVA, 2003). Por exemplo, o uso de fertilizantes tende ampliar a produtividade agrícola e, os países que não os produzem, importam.

Ainda, o emprego da tecnologia pode ser importante na determinação da qualidade dos produtos, fator tão importante quanto o preço em mercados diferenciados. Contudo, são necessários investimentos, em muitos casos vultuosos, muitas vezes baseados em expectativas futuras, que dependem do consumo e da renda, os quais podem ser influenciados pelo mercado externo, dentre outras coisas, como por exemplo, o crescimento gradual da população. Com o aumento da população tende a aumentar o que Keynes (1996) denomina de consumo autônomo, ou consumo sem renda. Trata-se de um aumento gradual que, apesar de muito inferior ao estimulo no consumo proporcionado pela renda, impacta na demanda e, consequentemente, na produção.

O crescimento da população está diretamente atrelado ao crescimento e ao desenvolvimento econômico. Malthus (1996) "defendia que o crescimento das nações está relacionado ao crescimento da população até um ponto onde se tornava insustentável”. Suas contribuições são importantes pontos de reflexão no sentido de registrar que "o crescimento desordenado acarretaria na falta de recursos alimentícios para a população gerando como consequência a fome”.

Contudo, com a Revolução Industrial as contribuições de Malthus perderam significância, pois a renda se elevava juntamente com a qualidade de vida das pessoas. Entretanto, as questões de sustentabilidade estão novamente a frente das principais pautas desenvolvimentistas, fato que reascende as considerações malthusianas. 
242 D. Dallemole; J. R. P. Manso; A. M. de M. Faria - Condicionantes da dinâmica produtiva ...

Independentemente de qual seja a base teórica, é sabido que há uma relação positiva entre crescimento econômico e crescimento demográfico; o que ainda não se tem certeza é até que ponto/quando isso é sustentável.

O fato é que há uma relação direta ou indireta entre produção, consumo, câmbio, exportação, importação, preço, tecnologia, renda e crescimento populacional. Em alguns casos ela é positiva, como no caso do consumo, em que seu aumento tende a ocasionar aumento da produção, ou negativa, como no caso das importações, em que seu aumento pode ocasionar indiretamente a queda da produção.

\section{Procedimentos metodológicos: modelo de dados em painel}

Os estudos com "Panel Data", ou dados em painel apresentam um horizonte significativamente amplo, considerando a dinamicidade do modelo e a facilidade de adaptação do mesmo as mais diversas temáticas socioeconômicas. De acordo com Hill, Griffiths e Lim (2007), a utilização de painéis de dados permite contabilizar ou ter em linha de conta as diferenças entre os países, isto é, permite apreciar a heterogeneidade e desta captar uma tendência para determinado mercado ou setor.

Os painéis de dados tendem a alongarem-se, permitindo que fatores dinâmicos importantes nos diversos mercados possam ser estudados. Neste caso, considerar-se-á as exportações, importações, consumo, produção, preço unitário pago ao produtor, PIB ou PIB per capita, tecnologia, taxas de câmbio e a população como condicionantes dos mercados de feijão e arroz.

A modelagem com dados em painel, apresenta vantagens sobre os estudos convencionais de séries temporais, tais como: aumento do número de pontos observados; elevação dos graus de liberdade; redução da multicolinearidade entre as variáveis explicativas; maior eficiência das estimativas, sendo mais adequado a estudos com mudanças dinâmicas. Em síntese, permite a identificação de parâmetros sem que sejam necessárias suposições restritivas aos mesmos (GREENE, 2003).

Um painel de dados é composto por um grupo de unidades seccionais que se observam ao longo do tempo e permite avaliar o comportamento de determinados sistemas produtivos ou mercados específicos. Neste caso, a aplicação do modelo proposto compilará informações relativas ao comportamento dos mercados de feijão e arroz no período de 1996 à 2010 ( $\mathrm{T}=15)$, relacionando Argentina, Brasil, França, Itália, Holanda, Portugal e Espanha e Estados Unidos ( $\mathrm{N}=8)$, para que os condicionantes da produção sejam identificados.

Outra questão interessante relacionada com os dados em painel é a da estimação de modelos econométricos que descrevem o comportamento dos indivíduos ao longo do tempo. Este tipo de dados permite controlar ou ter na devida conta as diferenças entre países, estudar a dinâmica do ajustamento e, ainda, medir outros efeitos como alterações tecnológicas. Para cada tipo de dados deve ter-se em atenção não apenas as hipóteses que afetam os erros aleatórios do modelo, mas também as hipóteses acerca do se, como e quando os parâmetros devem mudar entre os 
indivíduos e entre os vários períodos temporais (HILL, GRIFFITHS e LIM, 2012).

Segundo Hsiao (2003) e Klevmarken (1989) estudos com base em dados em painel permitem: i) controlar a heterogeneidade ou diferenças entre os países, ii) tratar maior quantidade de informação, maior variabilidade, menor colinearidade entre variáveis, maior número de graus de liberdade e mais eficiência, iii) permite o estudo da dinâmica de ajustamento ao longo do tempo, iv) têm maior capacidade para identificar e medir os efeitos puramente seccionais (cross-section) ou puramente cronológicos não detectados, $v$ ) permitem construir e testar modelos comportamentais mais complicados do que os cross-section ou time-series puros, vii) possibilitam reduzir ou eliminar o viés resultante da agregação de dados e viiii) por terem maiores crônicas e distinguirem o problema de distribuições não standard típicas dos testes de raízes unitárias na análise cronológica, os testes de raízes unitárias com dados de painel têm distribuições assintóticas estandardizadas.

Por outro lado, as limitações ou desvantagens dos modelos com dados em painel estão relacionados a: $i$ ) limitações decorrentes do design e da disponibilidade de dados, ii) erros de medida distorcidos, iii) problemas de seletividade, iv) dimensões temporais por vezes curtas e $v$ ) com dependência seccional ou 'cross-section' (HILL, GRIFFITTHS E LIM, 2012).

O modelo de dados em painel, em sua primeira etapa, requer a escolha entre os modelos de estimação, considerando os objetivos propostos e a base de dados empregada. De acordo com Marques,

[...] se o que se pretende é efectuar inferência relativamente a uma população, a partir de uma amostra aleatória da mesma, os efeitos aleatórios serão a escolha apropriada. Se se pretende estudar o comportamento de uma unidade individual em concreto, então os efeitos fixos são a escolha óbvia na medida em que é indiferente considerar-se a amostra como aleatória ou não [...] (MARQUES, 2012, P.21).

Os efeitos fixos são variáveis omitidas que variam entre os indivíduos, mas não ao longo do tempo (STOCK e WATSON, 2007). Como os efeitos fixos são constantes no decorrer do tempo, a influência desses efeitos é eliminada ao se fazer uma comparação entre períodos (modelo em diferenças), no qual apenas os fatores que variam entre períodos para explicar a variável dependente são considerados. De acordo com Loureiro e Costa (2009), o estimador de between torna-se adequado, pois leva em consideração somente a variação entre as unidades observacionais. Pode ser estimado da seguinte forma:

$$
\bar{y}_{i}=\bar{x}_{i} \beta+c_{i}+\bar{\varepsilon}_{i}
$$

Entretanto, o modelo de efeitos fixos pretende, justamente, controlar o efeito destas variáveis omitidas, que variam entre indivíduos ou países e permanecem constantes ao longo do tempo. Supõe-se que as intersecções variam de país para 
244 D. Dallemole; J. R. P. Manso; A. M. de M. Faria - Condicionantes da dinâmica produtiva ...

país, mas são constantes ao longo do tempo. Stock e Watson (2007), para eliminar a multicolinearidade entre países sugere a estimação do seguinte modelo:

$$
y_{i t}=\alpha_{i}+\beta_{1} x_{1 i t}+\beta_{2} x_{2 i t}+\cdots+\beta_{k} x_{k i t}+u_{i t}
$$

em que:

$\mathrm{i}=1,2, . ., 7$;

$\mathrm{t}=1996, \ldots ., 2010$.

O modelo de efeitos fixos, em parte, permite a existência de correlação entre os efeitos individuais não-observados com as variáveis incluídas, contudo, se os efeitos forem estritamente não-correlacionados com as variáveis explicativas, o modelo de efeitos aleatórios torna-se mais adequado. Recomenda-se o uso de Mínimos Quadrados Generalizados (MQG) para minimizar os possíveis problemas de autocorrelação. De acordo com Stock e Watson (2007), a estimação é feita introduzindo a heterogeneidade dos indivíduos no termo de erro:

$$
Y_{i t}=a+b X_{i t}+\left(n_{i}+u_{i t}\right)
$$

em que: $\eta_{i}$ representa o efeito aleatório individual não observável.

$\mathrm{O}$ processo de escolha entre os modelos pode ser suportada pelo Teste de Hausman, que se baseia na "comparação dos parâmetros estimados pelas duas especificações, tendo como hipótese nula a indicação para utilização do modelo de estimação com efeitos aleatórios”, ou seja, quando a probabilidade de aceitação da hipótese nula for superior a $5 \%$, tem-se o indicativo de que o modelo de efeitos aleatórios é mais adequado pois apresentará resultados mais consistentes. O Teste de Hausman é apresentado pela seguinte equação matemática:

$$
W=\frac{\left(b_{1}-\beta_{1}\right)^{2}}{\left[\operatorname{VAR}\left(B_{i}\right)-\operatorname{VAR} \beta_{i}\right]} \sim X_{(k)}^{2}
$$

em que:

$b_{1}$ é o estimador de efeitos fixos;

$\beta_{1}$ o estimador de efeitos aleatórios.

Neste estudo, com o modelo de dados em painel, a variável dependente (ou explicada) é a produção, no caso do feijão e arroz, por meio das demais variáveis consideradas independentes (ou explicativas): o consumo (C), as importações $(\mathrm{M})$, as exportações $(\mathrm{X})$, o preço da tonelada $(\mathrm{P})$, o PIB ou o PIB per capita a preços constantes $(\mathrm{Y})$, a evolução tecnológica $(\mathrm{T})$, por meio de uma proxy e uma Trend, 
bem como, a taxa de câmbio (E) e a população $(\mathrm{N})$.

Os erros deste modelo estão sujeitos às seguintes hipóteses: $i)$ valor médio nulo $E$, ii) homocedasticidade ou constância das variâncias, e iii) não correlação dos erros ao longo do tempo, . Os efeitos fixos deste modelo são medidos por um coeficiente por país que nos dá o desvio de cada país em relação à intersecção comum C.

Pode testar-se a hipótese de os valores dos efeitos fixos não variarem de país para país (efeitos constantes, iguais ou redundantes) por meio do teste de Chow, que avalia a estabilidade do modelo e identifica as mudanças estruturais ao longo do período de estimação. Para a estimação do modelo são utilizados dados disponíveis na Food and Agriculture Organization (FAO), Instituto Brasileiro de Geografia e Estatística (IBGE), Gabinete de Estatísticas da União Europeia (EUROSTAT), Fundo Monetário Internacional (International Monetary Fund, IMF) e Banco Mundial (World Bank). Os parâmetros e testes serão estimados por meio do software Eviews 7.

As estimativas foram realizadas considerando dois grupos de informações: no primeiro momento foram incorporadas ao modelos todas as categorias relacionadas, no intuito de obter os principais condicionantes da produção das referidas commodities, cujos resultados foram compilados em uma matriz, com a devida significância dos testes. No segundo momento foi incorporado uma variável Trend para tentar captar o efeito de algo que esteja em constante evolução, como é o caso da tecnologia, cujos resultados foram igualmente expostos em uma segunda matriz, para a realização das análises.

\section{Determinantes da oferta de feijão e arroz}

Os resultados obtidos expressam comportamentos específicos em alguns casos, entretanto, semelhantes em outros. Este fator ainda é impulsionado pelos aspectos culturais, diversos entre o grupo de países analisados, o que dificulta o entendimento de alguns comportamentos, entretanto, elucida algumas preferências e tendências em relação as alterações das categorias econômicas analisadas neste estudo.

A distribuição do resultado em duas matrizes foi realizada intencionalmente para atender a especificidade dos objetivos e da base teórico-metodológica que pretende, entre os condicionantes da oferta, identificar também a importância da evolução tecnológica na produção de feijão e arroz. Na Tabela 5 os resultados apresentam as relações das principais categorias econômicas com a produção das commodities em questão e a influência destas na produção, enquanto que na Tabela 6 foi incorporada a variável Trend como proxy de algo que esteja em constante evolução, como a base tecnológica e a importação de fertilizantes, utilizados no processo produtivo.

No modelo sem a Trend os resultados apontam o câmbio, o consumo, as exportações, o PIB per capita e o preço como sendo as categorias mais importantes na determinação da oferta dos produtos analisados, sendo significativas em $75 \%$ dos resultados, como pode ser observado na Tabela 5 . Na sequência, a população é significativa em $50 \%$ dos casos e o uso de fertilizantes apresenta apenas $25 \%$ de 
246 D. Dallemole; J. R. P. Manso; A. M. de M. Faria - Condicionantes da dinâmica produtiva ...

frequência. As importações não são significativas em nenhum dos casos, portanto, não se apresentam como condicionantes da produção de feijão e arroz.

Em todos os eventos, a estatística descritiva atestou a significância do modelo, apresentando o R-Quadrado dentro dos parâmetros aceitáveis, assim como a estatística F e o valor da estatística de Durbin-Watson. Com relação ao modelo de dados em painel, o processo de escolha entre o modelo de efeitos fixos e o modelo de efeitos aleatórios foi determinado pelo Teste de Hausman, com probabilidade de aceitação da hipótese nula superior a $5 \%$ e o indicativo de que o modelo de efeitos aleatórios é mais adequado e apresenta resultados mais consistentes.

No que tange aos coeficientes estimados, as exportações apresentam correlação positiva, tanto no modelo de efeitos fixos, como no modelo de efeitos aleatórios, exceto para feijão no modelo de efeitos fixos. Contudo, o Teste de Hausman indica que o modelo de efeitos aleatórios é o mais adequado e possui resultados mais consistentes referente as exportações e sua influência sobre a produção de feijão e arroz.

A correlação positiva encontrada para feijão $(0,511502)$ e arroz $(0,521477)$ indica que o aumento das exportações gera expectativas positivas sobre o setor produtivo, o que tende a estimular o aumento da produção futura. Supondo que haja um aumento de uma tonelada nas exportações de cada commodity, o incremento na produção tende a ser de 0,51 tonelada para feijão e 0,52 toneladas para arroz. 
Tabela 5 Matriz de Resultados para Feijão e Arroz, 1996 a 2010, significativo a 5\%.

\begin{tabular}{|c|c|c|c|c|}
\hline \multirow[t]{2}{*}{ NOTAÇÃO } & \multicolumn{2}{|c|}{$\begin{array}{l}\text { MODELO DE EFEITOS } \\
\text { FIXOS }\end{array}$} & \multicolumn{2}{|c|}{$\begin{array}{c}\text { MODELO DE EFEITOS } \\
\text { ALEATÓRIOS }\end{array}$} \\
\hline & Feijão & Arroz & Feijão & Arroz \\
\hline Intercepto C & $8.351859 *$ & $\mathrm{~N} / \mathrm{S}$ & 4.324782 & -12.86615 \\
\hline Câmbio & 0.091058 & $\mathrm{~N} / \mathrm{S}$ & 0.089602 & -0.068321 \\
\hline Consumo & 0.243800 & $\mathrm{~N} / \mathrm{S}$ & 0.377474 & 1.842777 \\
\hline Exportação & $\mathrm{N} / \mathrm{S}$ & 0.070386 & 0.511502 & 0.521477 \\
\hline Importação & $\mathrm{N} / \mathrm{S}$ & $\mathrm{N} / \mathrm{S}$ & $\mathrm{N} / \mathrm{S}$ & $\mathrm{N} / \mathrm{S}$ \\
\hline PIB Per Capita & $\mathrm{N} / \mathrm{S}$ & 0.477301 & -1.721125 & -1.083463 \\
\hline População & $\mathrm{N} / \mathrm{S}$ & N/S & 1.039818 & 3.420722 \\
\hline Preço & -0.278092 & $\mathrm{~N} / \mathrm{S}$ & -0.378259 & 3.365276 \\
\hline Fertilizantes & $\mathrm{N} / \mathrm{S}$ & $\mathrm{N} / \mathrm{S}$ & $\mathrm{N} / \mathrm{S}$ & -2.631333 \\
\hline R-Quadrado & 0.989557 & 0.999472 & 0.968573 & 0.761546 \\
\hline Estatística F & 710.7169 & 14189.18 & 493.1099 & 51.09891 \\
\hline Probabilidade $(\mathrm{F})$ & 0.000000 & 0.000000 & 0.000000 & 0.000000 \\
\hline Durbin-Watson & 1.058834 & 1.577224 & 0.951693 & 0.312731 \\
\hline Efeitos Redundantes Prob. $\left(\chi^{2}\right)$ & 0.0000 & 0.0000 & N/A & N/A \\
\hline Estatística F & 493.1099 & 51.09891 & $\mathrm{~N} / \mathrm{A}$ & $\mathrm{N} / \mathrm{A}$ \\
\hline Estatística Qui-quadrado & 132.21521 & 733.47379 & $\mathrm{~N} / \mathrm{A}$ & $\mathrm{N} / \mathrm{A}$ \\
\hline Teste de Hausman Prob. $(\chi 2)$ & N/A & N/A & 0.0000 & 0.0000 \\
\hline Estatística Qui-quadrado & $\mathrm{N} / \mathrm{A}$ & N/A & 211.00387 & 47288.5731 \\
\hline
\end{tabular}

Fonte: Eviews, 2013. Legenda: N/S = Não Significativo N/A = Não Aplicável * Significativo a 10\%

Os países estudados computaram um aumento médio nas exportações deste grupo de produtos relativamente pequeno entre 1996 a 2010. Os coeficientes obtidos com o modelo ratificam essa tendência e indicam que, mesmo assim, não está assegurada a proporcionalidade entre a variação na exportação e na produção. Significa que o incremento na produção não atende o montante adicionado das exportações e a complementação pode estar ocorrendo via aumento de importações, ou diminuição do consumo via substituição, o que é perfeitamente possível em mercados globalizados e competitivos. Entretanto, as importações não foram significativas em nenhum dos casos.

Ainda, o consumo apresentou-se como outra variável importante para a explicação do comportamento da oferta de feijão (0.377474) e arroz (1.842777), considerando o modelo de efeitos aleatórios. A correlação positiva indica que o incremento no consumo tende a impactar positivamente na produção, estimulando o seu aumento, principalmente no caso do arroz, que responde com 1,8 toneladas a 
cada incremento de uma tonelada no consumo. Isso tende a ocorrer em virtude da magnitude do mercado de arroz, atualmente consumido no mundo inteiro e cada vez mais se destacando como o principal produto na base da alimentação, inclusive, em substituição a batata em muitos países.

No caso do feijão, o modelo revelou a mesma tendência, entretanto, o consumo de feijão caiu na maioria dos países analisados, principalmente, no seu maior consumidor, o Brasil. O que chama a atenção é o fato de, em algumas regiões brasileiras, haver certa complementariedade com o arroz, que apresentou aumento no consumo, apesar de não muito expressivo. Contudo, o modelo com dados em painel revela que o consumo de feijão é um condicionante importante, que exprime uma tendência positiva em estimular o aumento da produção.

O câmbio apresenta uma correlação positiva somente para o feijão (0.089602), indicando que o aumento da taxa de câmbio favorece as exportações, estando coerente ao comportamento do mercado, uma vez que neste caso ocorre a valorização da moeda internacional e o aumento poder de compra dos exportadores. $\mathrm{O}$ mesmo não ocorre com o arroz (-0.068321), cuja sinalização negativa indica que o aumento da taxa de câmbio desestimula a produção. Entretanto, este aumento da taxa de câmbio interfere positivamente nas exportações que, mesmo assim, apresentam elevação, provavelmente em virtude de outros fatores que se sobrepõem.

Um dos fatores que pode explicar o aumento do consumo e das exportaçóes de arroz é o preço, que manteve-se estável, apresentando aumento médio de apenas 3\% entre 1996 a 2010. Percentual significativamente baixo, se comparado com o do feijão, que apresentou um aumento médio de preços de $34 \%$ no referido período. Considerando os coeficientes do modelo, o preço apresentou-se como significativo para feijão (-0.314901), entretanto, com indicação negativa, o que pode não estar ajustado a um modelo de determinação da oferta, mas exprime uma tendência de queda no consumo, como no caso do feijão. Para o arroz, o preço não se mostra significativo, portanto, não há o registro de implicações significativas, uma vez que as exportações, o consumo e a produção de arroz aumentaram, juntamente com os preços.

A tendência crescente do aumento populacional também tem participação no incremento da oferta ao longo do período analisado. $\mathrm{O}$ aumento populacional causa impacto na produção de feijão $(1,03981)$ e arroz $(3,42072)$, também em virtude do consumo autônomo nos países analisados, uma vez que o incremento da renda não é significo para estes produtos. O PIB per Capita apresenta correlação negativa para feijão e arroz, indicando que o incremento na renda implica em diminuição na produção, fato convergente às concepções da teoria econômica, que classifica estes produtos como bens substitutos.

A fertilidade do solo é importante para todas as culturas, entretanto, não apresenta uniformidade entre as regiões produtoras do mundo. A necessidade de complementação por meio da adubação química ou orgânica é fundamental para o cultivo em solos de pouca fertilidade, como é o caso do cerrado brasileiro, uma das principais regiões produtoras de grãos do mundo. Trata-se de uma realidade distin- 
ta à norte-americana, considerando que os EUA possui a maior extensão de terras férteis, economicamente exploráveis do mundo, fator que o ajuda a se manter no topo da produção mundial de commodities. Tanto na Argentina quanto nos países europeus estudados, a fertilidade média também é superior, o que determina menores níveis de necessidade de complementação com uso de fertilizantes.

Além do uso de fertilizantes, a produção ainda pode ser impactada pelo ganho tecnológico, que otimiza ou torna mais eficiente os processos de plantio e tratos culturais, além do melhoramento genético das espécies. Com relação aos fertilizantes, sua importação pelos países foi utilizada como proxy para avaliar a importância do uso de fertilizantes como determinante da produção. Já para a evolução tecnológica foi empregada uma variável Trend, evolutiva de 1996 a 2010.

$\mathrm{O}$ uso de fertilizantes apresentou-se significativo para arroz (-2.6313), sem o uso da Trend. Contudo, apresenta uma correlação negativa, indicando que o aumento em seu uso tende a diminuir a produção, o que não condiz com a realidade e, portanto, presume-se que a autocorrelação entre as variáveis seja responsáveis por esta anomalia.

Ao considerar os resultados com a inserção da variável Trend, expostos na Tabela 6, a influência desta proxy para a tecnologia altera os resultados, diminuindo a importância dos principais condicionantes da oferta. Trata-se de uma tendência apresentada pela própria variável, que é significativa para feijão, com correlação negativa, o que significaria que o incremento de tecnologia não seria importante na determinação da produção de feijão, tanto para o modelo de efeitos fixos, quanto para o modelo de efeitos aleatórios. 
Tabela 6. Matriz de Resultados para Feijão e Arroz, 1996 a 2010, com Trend, significativo a $5 \%$.

\begin{tabular}{|c|c|c|c|c|}
\hline \multirow[t]{2}{*}{ NOTAÇÃO } & \multicolumn{2}{|c|}{$\begin{array}{l}\text { MODELO DE EFEITOS } \\
\text { FIXOS } \\
\end{array}$} & \multicolumn{2}{|c|}{$\begin{array}{c}\text { MODELO DE EFEITOS } \\
\text { ALEATÓRIOS }\end{array}$} \\
\hline & Feijão & Arroz & Feijão & Arroz \\
\hline Intercepto C & -17.08755 & $\mathrm{~N} / \mathrm{S}$ & $\mathrm{N} / \mathrm{S}$ & -6.535430 \\
\hline Câmbio & 0.046561 & $\mathrm{~N} / \mathrm{S}$ & 0.053707 & $\mathrm{~N} / \mathrm{S}$ \\
\hline Consumo & 0.208671 & $\mathrm{~N} / \mathrm{S}$ & 0.239138 & 0.382415 \\
\hline Exportação & $\mathrm{N} / \mathrm{S}$ & 0.072339 & $\mathrm{~N} / \mathrm{S}$ & 0.108577 \\
\hline Importação & $\mathrm{N} / \mathrm{S}$ & $\mathrm{N} / \mathrm{S}$ & $\mathrm{N} / \mathrm{S}$ & $\mathrm{N} / \mathrm{S}$ \\
\hline PIB & $\mathrm{N} / \mathrm{E}$ & $0.379365 \%$ & $\mathrm{~N} / \mathrm{E}$ & -1.118747 \\
\hline PIB Per Capita & $\mathrm{N} / \mathrm{S}$ & $\mathrm{N} / \mathrm{E}$ & -0.783747 & $\mathrm{~N} / \mathrm{E}$ \\
\hline População & 4.282330 & $\mathrm{~N} / \mathrm{S}$ & 1.457656 & 3.358551 \\
\hline Preço & -0.335352 & $\mathrm{~N} / \mathrm{S}$ & -0.314901 & $\mathrm{~N} / \mathrm{S}$ \\
\hline Fertilizantes & $\mathrm{N} / \mathrm{S}$ & $\mathrm{N} / \mathrm{S}$ & $\mathrm{N} / \mathrm{S}$ & $\mathrm{N} / \mathrm{S}$ \\
\hline Trend & -0.336635 & $\mathrm{~N} / \mathrm{S}$ & -0.157411 & $\mathrm{~N} / \mathrm{S}$ \\
\hline R-Quadrado & 0,991277 & 0.999459 & 0.575118 & 0.463734 \\
\hline Estatística F & 852.2989 & 13848.64 & 21.65748 & 13.83591 \\
\hline Probabilidade $(\mathrm{F})$ & 0.000000 & 0.000000 & 0.000000 & 0.000000 \\
\hline Durbin-Watson & 1.143102 & 1.530219 & 0.955277 & 0.211354 \\
\hline Efeitos Redundantes Prob. $\left(\chi^{2}\right)$ & 0.00000 & 0.00000 & $\mathrm{~N} / \mathrm{A}$ & $\mathrm{N} / \mathrm{A}$ \\
\hline Estatística F & 153.0701 & 58.90485 & N/A & $\mathrm{N} / \mathrm{A}$ \\
\hline Estatística Qui-quadrado & 286.08851 & 717.35411 & $\mathrm{~N} / \mathrm{A}$ & $\mathrm{N} / \mathrm{A}$ \\
\hline Teste de Hausman Prob. $(\chi 2)$ & $\mathrm{N} / \mathrm{A}$ & $\mathrm{N} / \mathrm{A}$ & 0.0003 & 0.0000 \\
\hline Estatística Qui-quadrado & $\mathrm{N} / \mathrm{A}$ & $\mathrm{N} / \mathrm{A}$ & 27.48038 & 678.09986 \\
\hline
\end{tabular}

Fonte: Eviews, 2013. Legenda: N/S = Não Significativo N/E = Não Estimado N/A = Não Aplicável $*$ Significativo a $10 \%$

O principal fato é que a variável Trend não se ajusta ao modelo adequadamente, pois as principais categorias que se apresentam como importantes condicionantes da produção não mantém o mesmo nível de significância e apresentam alteração no sinal, tornando-se, inclusive, contrárias às concepções da Teoria Econômica. Mesmo assim, o consumo e as exportações se mantém como os principais condicionantes da produção, tanto no modelo de efeitos fixos, quanto no modelo de efeitos aleatórios. Apenas a exportação deixa de ser significativa para feijão. 
Contudo, o objetivo com o uso da Trend não é contemplado na condição desejável para que se possa estabelecer a devida importância da tecnologia, assim como ocorre com a variável fertilizantes, cuja importação pelos países estudados foi utilizada, também como proxy para captar o efeito de sua utilização na produção. Apenas agrega às categorias analisadas a significância do PIB como condicionante da produção de arroz (0.379365) a nível 10\%. Neste caso, o crescimento econômico tem impulsionado a produção de arroz, mesmo que em menor grau.

De modo geral, os indicadores obtidos nas estimativas sem o uso da Trend são mais consistentes para a explicação do comportamento da oferta de feijão e arroz nos países estudados. Este fator não minimiza a importância da tecnologia e do uso de fertilizantes no processo produtivo, apenas atesta que estas proxys não são adequadas para captar este tipo de efeito.

\section{Considerações finais}

Os resultados disponibilizam informações importantes acerca dos fatores responsáveis pelas atuais condições dos mercados de feijão e arroz, bem como, a possibilidade de visualizar tendências futuras relacionadas a seguridade alimentar, uma vez que se tratam de dois produtos fundamentais para a nutrição humana. Criam-se, portanto, externalidades positivas para engajamento de diversas áreas do conhecimento, visando construir massa crítica para operar em mercados globalizados. A possibilidade de serem criados cenários futuros para os referidos mercados auxilia o setor produtivo a estar mais organizado e preparado para manter-se, ou inserir-se em mercados mais competitivos.

A correlação positiva apresentada pelo modelo para as exportações indica que seu aumento gera tendências de crescimento econômico. Isso não ocorre somente via ingresso de capital externo, uma vez que o aumento de exportações também gera impactos sobre o mercado interno. Há aumento do emprego e da renda, que estimula a compra de bens e serviços, além de insumos que, em grande parte, são fornecidos pelas empresas locais. O modelo identifica a importância das exportações como fator de incentivo à produção de feijão e arroz, um resultado que pode ocasionar outros rebatimentos, uma vez que nenhuma atividade de base exportadora se desenvolve sem trazer consigo, por exemplo, o fortalecimento da infraestrutura portuária, de transportes, ou até mesmo de comunicações. Trata-se de um efeito multiplicador que pode apresentar uma densidade significativa de impactos socioeconômicos, que merece atenção quando da elaboração de políticas de incentivo à produção agropecuária para comercialização em mercados globalizados.

De suma importância no fortalecimento das exportações, o câmbio exerce uma função estratégica no enfrentamento de problemas de mercado, como baixa competitividade ou, simplesmente, na definição de preços mais atrativos para os produtos. $\mathrm{O}$ câmbio se apresenta como um condicionante importante no estimulo a produção e, dada sua relação com as exportações, uma política cambial eficaz é 
fundamental para o fortalecimento do mercado, gerando expectativas positivas em relação ao crescimento da atividade econômica. Isso ocorre não somente em virtude do aumento da produção de feijão e arroz, mas também pelo incentivo que uma medida desta natureza pode causar no mercado de commodities como um todo.

$\mathrm{O}$ modelo de dados em painel revelou que o consumo possui uma correlação positiva e significativa com a produção, principalmente para o arroz. Entretanto, qualquer política econômica de incentivo ao consumo deve ter a precaução com. $\mathrm{O}$ aumento do consumo, tendencialmente, ocorre em virtude do fortalecimento do poder de compra da sociedade, algo que pode ter sua origem na elevação do nível de renda, que se atrelada a valorização da moeda doméstica, tende a reduzir a competitividade dos produtos nacionais no mercado internacional e fortalecer as importações.

Outro ponto que requer atenção é o fato da renda não ter sido considerada um condicionante importante para o mercado de feijão ou arroz. É imprescindível para que haja aumento do consumo, contudo, não estimula diretamente a produção nos mercados avaliados. Para que haja crescimento econômico é necessário que a renda aumente, fator que tem ocorrido nestes mercados tendo em vista o aumento do consumo e das exportações de feijão e arroz de forma significativa, para importações com menor nível de significância, de acordo com os dados e os resultados apontados pelo modelo.

O aumento de preços não é uma característica exclusiva destes mercados, mas sim uma necessidade de reprodução do sistema. No entanto, os preços do feijão apresentaram uma tendência contrária, o que é compreensível, por se tratar de uma bem substituto. O que se pode perceber é que o efeito do preço d do feijão e do arroz não segue a mesma tendência dos impactos gerados pelo câmbio, exportações e consumo, fator este que recomenda uma política de preços moderados para estes produtos, no sentido de manter o equilíbrio nestes mercados. Se houver uma valorização significativa das commodities, a produção de feijão pode apresentar uma tendência de queda em detrimento da produção de outras culturas.

Outro fator natural de estímulo ao incremento da produção de feijão e arroz apresenta-se como importante condicionante: o aumento populacional. Contudo, isso não significa que a taxa de crescimento populacional seja responsável pela geração de crescimento econômico, ou que deva ser estimulado como já fora outrora. Naturalmente, gera impacto positivo no consumo, cujos efeitos já foram apresentados, entretanto, abre caminho para discussões mais amplas, relacionadas a sustentabilidade dos processos e abastecimento destes produtos, considerados fundamentais no combate à fome em alguns países como, por exemplo, o Brasil.

$\mathrm{O}$ abastecimento é um dos principais gargalos relacionados à necessidade de se ampliar a produção. Para que a seguridade alimentar se torne uma realidade, também, é necessária uma distribuição mais equacionada dos alimentos. Nesse sentido, qualquer política destinada a otimizar os processos de produção e distribuição destas commodities deve considerar os aspectos inter-relacionados referentes a produção, transporte e comercialização. No que se refere aos mercados de feijão e 
arroz, todos os elos da cadeia são importantes, por isso, qualquer política de incentivo deve ter um caráter moderado para que este equilíbrio se apresente como uma tendência natural, pois somente dessa forma será possível aproximar o mercado de alimentos da sua genuína função.

\section{Referências}

BLANCHARD, O. Macroeconomia. 5 Ed. São Paulo: Pearson Education, 2011.

CARIO, S. A. F. Contribuição do Paradigma Microdinâmico Neoschumpeteriano à Teoria Econômica Contemporânea. Florianópolis: Textos de Economia, p.155-170, 1995.

CONAB, Companhia Nacional de Abastecimento. Estudos de Prospeç̧ão de Mercado. Conab: Brasília, 2013.

DALLEMOLE, D. Comércio Exterior Brasileiro: a incapacidade de auto-proteção do mercado interno. 126f. Dissertação (Mestrado em Planejamento do Desenvolvimento). Núcleo de Altos Estudos Amazônicos, Universidade Federal do Pará, Belém, 2003.

EUROSTAT, Gabinete de Estatísticas da União Europeia. Disponível em: http:// epp.eurostat.ec.europa.eu/portal/page/portal/eurostat/home/. Acesso em: 17 out. 2012.

FAO, Food and Agriculture Organization of the United Nations. Disponível em: http:// faostat3.fao.org/home/index.html\#DOWNLOAD. Acesso em: 10 out. 2012.

GREENE, W.H. Econometric analysis. 5. Ed. Singapore: Pearson Education, 2003.

GUIMARÃES, E. P. Uma Avaliação Retrospectiva da Política de Exportação no Brasil. Disponível em: <http://www.ie.ufrj.br/ecex/h_v1n1.htm>. Acesso em: $10 \mathrm{Jul}$. 2001.

HILL, R. C., GRIFFITHS, W. E. e LIM, G.C. Principles of Econometrics, 4 Ed. Wiley, 2012.

HSIAO, C. Analysis of Panel Data. Second Ed. Cambridge: University Press, 2003. erossef http://dx.doi.org/10.1017/CBO9780511754203

IBGE, Sistema IBGE de Recuperação Automática. Disponível em: http://www. sidra. ibge.gov.br/. Acesso em: 14 out. 2012. 
254 D. Dallemole; J. R. P. Manso; A. M. de M. Faria - Condicionantes da dinâmica produtiva ...

IMF, International Monetary Fund. Disponivel em: http://www.imf.org/external / pubs/ ft/weo/2012/02/ weodata/weoselgr.aspx. Acesso em: 12 out. 2012.

KEYNES, J. M. A Teoria Geral do Emprego, do Juro e da Moeda. São Paulo: Nova Cultural, 1996.

KLEVMARKEN, N. A. Introduction: Panel Studies. European Economic Review, Elsevier, vol. 33(2-3), pages 523-529, March, 1989. Crosses http://dx.doi. org/10.1016/0014-2921(89)90131-1

LOUREIRO, A. O. F.; COSTA, L. O. Uma Breve Discussão Sobre os Modelos com Dados em Painel. Ceará: IPECE, Nota Técnica N³7, 2009.

MALTHUS, T. R. Ensaio Sobre a População. São Paulo: Nova Cultural, 1996. (Coleção Os Economistas).

MARQUES, L. D. Modelos Dinâmicos com Dados em Painel: revisão de literatura. Disponível em: http://wps.fep.up.pt/wps/wp100.pdf. Acesso em: 10 out. 2012.

MARX, KARL. O Capital: crítica da economia política. São Paulo: Nova Cultural. Volume 1, livro primeiro, 1996. (Coleção Os Economistas).

PINDYCK, R. S.; RUBINFELD, D. L. Microeconomia. $7^{\text {a }}$ Ed. São Paulo: Prentice Hall, 2010.

RATTI, B. Comércio Internacional e Câmbio. São Paulo: Aduaneiras, 2004.

SILVA, J. G. Tecnologia e Agricultura Familiar. $2^{\mathrm{a}}$ Ed. Porto Alegre: UFRGS, 2003.

STOCK, J. H.; WATSON, M. W. Introduction to Econometrics. 2 Ed. Addison-Wesley, Reading, MA, 2007.

USDA, United States Department of Agriculture. Disponível em: http://www.ars. usda.gov/main/site_main.htm? modecode=12-35-45-00. Acesso em: 10 abr. 2013.

WORLD BANK, World Data Bank. Disponível em: http://databank.worldbank. org /data/home.aspx. Acesso em: 15 out. 2012. 